\title{
Further studies on the marine tardigrade fauna from Sardinia (Italy)
}

\author{
Rossana D'ADDABBO, Maria GALLO*, Cristiana DE LEONARDIS, Roberto SANDULLI and \\ Susanna DE ZIO GRIMALDI
}

Zoology Department, University of Bari, Via Orabona 4, 70125 Bari, Italy

*e-mail corresponding author: m.gallo@biologia.uniba.it

\begin{abstract}
An investigation on the taxonomy and ecology of marine tardigrades was carried out in different intertidal and subtidal sites along the coasts of Sardinia (Italy). Particle size analysis of sediments revealed medium or medium-fine intertidal sands and coarse subtidal sands, the latter mainly formed by coralligenous debris. The systematic study was particularly relevant, leading to the identification of 25 species, of which 9 are new records for Sardinia, and 2 are new to science. With these new findings, the total number of species for Sardinia adds up to 47. The species found belong to the families Halechiniscidae (16 species; abundance 2 to 263 ind. $\left.10 \mathrm{~cm}^{-2}\right)$, Batillipedidae (6 species; abundance 2 to 574 ind $10 \mathrm{~cm}^{-2}$ ) and Stygarctidae ( 3 species; abundance 0 to 13 ind. 10 $\left.\mathrm{cm}^{-2}\right)$. The present data confirm the existence of a remarkable diversity, both of intertidal and subtidal tardigrade fauna. Generally, the prevalently siliceous intertidal sands host a few number of species (sometimes with many individuals), while the subtidal sediments, which were mainly calcareous, show a higher number of species often with low density. In fact, in the intertidal sediments only 11 species were found, 5 belonging to Halechiniscidae and 6 to Batillipedidae. In the subtidal sediments, there was a much wider variety; Halechiniscidae showed the highest number of species (16), compared to the remaining families, while Stygarctidae, which were present only in subtidal sediments, accounted only for 3 species. In the intertidal zone the highest value of the diversity index $\left(H^{\prime}\right)$ was 2.1 and in the subtidal zone it was 3.3.
\end{abstract}

Key words: Tardigrada, Heterotardigrada, Sardinia, Biodiversity

\section{INTRODUCTION}

The first records of marine tardigrades in Sardinia date back to 1964 when Batillipes pennaki Marcus, 1926 was found on the sandy beaches of the S. Marinella Gulf and S. Reparata Bay near Sassari (de Zio 1964; Grimaldi 1965). Since then, data about the Sardinian fauna have successively been obtained from different coastal localities intertidally and subtidally, with each revealing a high species richness, particularly in subtidal sediments (Grimaldi de Zio et al. 1983, 1988, 1990a, b; D'Addabbo Gallo et al. 1989, 1992; de Zio Grimaldi et al. 1992, 2003; Gallo D'Addabbo et al. 1999, 2005; de Zio Grimaldi \& D'Addabbo Gallo 2001; Hansen et al. 2003).

With the exploration of 9 localities of the northern and western coast (Alghero, Asinara Gulf) and 9 new sites of the Orosei Gulf, our present study includes additional information about Sardinian tardigrade fauna.

\section{METHODS}

Sediment samples were obtained by direct hand coring $\left(6.2 \mathrm{~cm}^{2}\right)$ at depths ranging from 1 to $30 \mathrm{~m}$, via SCUBA diving for the subtidal collection, from five sites in the Alghero Gulf, four sites in the Asinara Gulf (July 2005), and from nine sites in the Orosei Gulf (June 2002) (Fig. 1). Samples were treated with $7 \% \mathrm{MgCl}_{2}$ solution to anesthetize the animals and then preserved with $5 \%$ formalin/seawater. The animals were extracted by washing in tap water and collecting them on a $42 \mu \mathrm{m}$ mesh size sieve. Kaiser's glycerol-gelatin or Hoyer's fluid were used for making permanent mounts (Higgins $\&$ Thiel 1988). Identification and taxonomic studies on tardigrades were performed with a light microscope (Leica DM 2500) equipped with phase contrast and interference contrast. Abundance of tardigrades collected via $6.2 \mathrm{~cm}^{2}$ corer, was calculated from the surface area sampled and reported to number of individuals per 10 $\mathrm{cm}^{2}$. In addition, Shannon-Wiener's diversity $\left(\mathrm{H}^{\prime}\right)$ and Pielou's indices $\left(\mathrm{J}^{\prime}\right)$ were calculated. Sediment was analysed for granulometry.
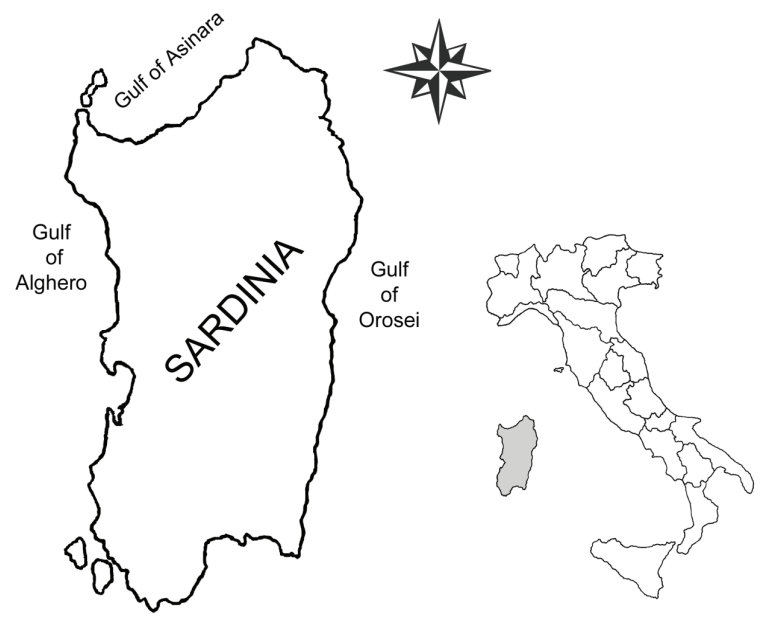

Fig. 1. Location map of Sardinia (Italy) sampling localities. 
Tab. 1. Tardigrada species, number of specimens, density and diversity per site in the Sardinia Island. CS = coarse sand; MS = medium sand; MFS = medium fine sand; FS = fine sand. $\mathrm{H}^{\prime}=$ Shannon-Wiener index; $\mathrm{J}^{\prime}=$ Pielou's index.

\begin{tabular}{|c|c|c|c|c|c|c|c|c|c|c|c|c|c|c|c|c|c|c|}
\hline & & & nero & Gulf & & & Asina & $\mathrm{ra} \mathrm{Gul}$ & & & & & & sei $\mathrm{G}$ & Sulf & & & \\
\hline Site & 1 & 2 & 3 & 4 & 5 & 6 & 7 & 8 & 9 & 10 & 11 & 12 & 13 & 14 & 15 & 16 & 17 & 18 \\
\hline Depth & 0 & 1 & 1 & 0 & 20 & 0 & 0 & 5 & 7 & 0 & 5 & 7 & 30 & 0 & 1 & 5 & 7 & 0 \\
\hline Mean Grain Size & & & & & 0.25 & 2.25 & 0.25 & 1 & .5 & & & 0.25 & & & 1.5 & 0.25 & 1.5 & 2.25 \\
\hline Sediment type & & & & & $\mathrm{CS}$ & MFS & $\mathrm{CS}$ & $\mathrm{M}$ & & & & $\mathrm{CS}$ & & & MS & CS & MS & MFS \\
\hline Taxa & & & & & & & & & & & & & & & & & & \\
\hline Stygarctidae & & & & & & & & & & & & & & & & & & \\
\hline Parastygarctus biungulatus Morone De Lucia et al., 1984 & & & & & 1 & & & & & & & & & & & & & \\
\hline Parastygarctus mediterranicus Gallo D'Addabbo et al., 2001 & & & & & & & & & & & & & 5 & & & & & \\
\hline Parastygarctus sterreri Renaud-Mornant, 1970 & & & & & 4 & & & & & & & & 3 & & & & & \\
\hline Halechiniscidae & & & & & & & & & & & & & & & & & & \\
\hline Dipodarctus subterraneus (Renaud-Mornant, 1959) & & & & 4 & 7 & & & & 2 & & & & 1 & & & & & \\
\hline Florarctus antillensis Van der Land, 1968 & & & & 5 & & & & & & & & & & & & & & \\
\hline Florarctus asper Renaud-Mornant, 1989 & & & & & & & & & & & & & 5 & & & & & \\
\hline Florarctus hulingsi Renaud-Mornant, 1976 & & & & 1 & 6 & & & & & & & & & & & & & \\
\hline Florarctus n. sp. & & & & 110 & & & & & & & & & & & & & & \\
\hline Halechiniscus greveni Renaud-Mornant \& Deroux, 1976 & & & 1 & & & 1 & 26 & 17 & 18 & 4 & 2 & 26 & 72 & & & & 6 & 8 \\
\hline Halechiniscus remanei Schulz, 1955 & & & & 43 & & & 2 & & & 2 & 16 & 18 & & & & & & 1 \\
\hline Halechiniscus tuleari Renaud-Mornant, 1979 & & & & & 7 & & & & & & & 4 & & & & & & \\
\hline Orzeliscus belopus Du Bois Reymond Marcus, 1952 & & & & & & & & 10 & 12 & & & & & & & 4 & 44 & \\
\hline Paratanarctus kristenseni D'Addabbo Gallo et al., 1992 & & & & & 2 & & & & & & & & & & & & & \\
\hline Styraconyx qivitoq Kristensen \& Higgins, 1984 & & & & & 7 & & & & & & & & & & & & & \\
\hline Styraconyx sardiniae D'Addabbo Gallo et al., 1989 & & & & & 1 & & & & & & & & 1 & & & & & \\
\hline Tholoarctus natans natans Kristensen \& Renaud-Mornant, 1983 & & & & & 2 & & & & & & & & & & & & & \\
\hline Actinarctus doryphorus Schulz, 1935 & & & & & 1 & & & & & & & & & & & & & \\
\hline Actinarctus physophorus Grimaldi de Zio et al., 1982 & & & & & 3 & & & & & & & & & & & & & \\
\hline Tanarctus gracilis Renaud-Mornant, 1980 & & & & & & & 2 & & & & & & & & & & & \\
\hline Batillipedidae & & & & & & & & & & & & & & & & & & \\
\hline Batillipes dicrocercus Pollock, 1970 & & & 5 & 2 & & 4 & & 5 & 4 & & 2 & & & & 12 & 4 & 2 & \\
\hline Batillipes littoralis Renaud-Debyser, 1959 & & & & 1 & 2 & & & 1 & & & & & 18 & & & & & 141 \\
\hline Batillipes pennaki Marcus, 1946 & 1 & & & 75 & & 50 & & 1 & & & & & & & & & & \\
\hline Batillipes similis Schulz, 1955 & & & & 4 & & & & 1 & 4 & & 2 & 10 & & & & & & \\
\hline Batillipes spinicauda Gallo D'Addabbo et al., 2005 & & 2 & & 2 & & & 8 & 125 & 122 & 2 & 10 & 16 & & 4 & 344 & 336 & 170 & \\
\hline Batillipes n. sp. & & & & 8 & & & & & & & & & & & & & & \\
\hline Total & 1 & 2 & 6 & 255 & 43 & 55 & 38 & 160 & 162 & 8 & 32 & 74 & 105 & 4 & 356 & 344 & 222 & 150 \\
\hline Species number & 1 & 1 & 2 & 11 & 12 & 3 & 4 & 7 & 6 & 3 & 5 & 5 & 7 & 1 & 2 & 3 & 4 & 3 \\
\hline Total Density (n. ind. $10 \mathrm{~cm}^{-2}$ ) & 2 & 3 & 10 & 411 & 69 & 89 & 61 & 258 & 261 & 13 & 52 & 119 & 169 & 6 & 574 & 555 & 358 & 242 \\
\hline $\mathrm{H}^{\prime}$ & 0 & 0 & 0.7 & 2.1 & 3.3 & 0.5 & 1.3 & 1.2 & 1.3 & 1.5 & 1.8 & 2.1 & 1.5 & 0 & 0.2 & 0.2 & 1 & 0.4 \\
\hline $\mathrm{J}^{\prime}$ & 0 & 0 & 0.7 & 0.6 & 0.9 & 0.3 & 0.6 & 0.4 & 0.5 & 0.9 & 0.8 & 0.9 & 0.5 & 0 & 0.2 & 0.1 & 0.5 & 0.2 \\
\hline
\end{tabular}

\section{RESULTS}

The systematic study revealed a total of 25 species (Tab. 1) belonging to 3 families: Stygarctidae (3 species), Halechiniscidae (16 species), and Batillipedidae (6 species). Of these, two species, recorded from the Alghero Gulf, are new to science: (Florarctus n. sp., and Batillipes n. sp.), while 9 other species are new records for Sardinia. The latter includes: Parastygarctus biungulatus Morone de Lucia et al., 1984, Parastygarctus mediterranicus Gallo D'Addabbo et al., 2001, Florarctus asper Renaud-Mornant, 1989, Florarctus antillensis Van der Land, 1968, Halechiniscus tuleari Renaud-Mornant, 1979, Tanarctus gracilis RenaudMornant, 1980, Actinarctus physophorus Grimaldi de Zio et al., 1982, A. doryphorus Schulz, 1935, and Batillipes spinicauda Gallo D'Addabbo et al., 2005. The highest number of species (21) was recorded in the Alghero Gulf, followed by the Orosei (13 species) and Asinara Gulfs (10 species). In intertidal sediments, 12 species were recorded, including 5 Halechiniscidae and 6 Batillipedidae. In subtidal sediments, 22 species were recorded, represented by 16 Halechiniscidae, 1 Batillipedidae, and 3 Stygarctidae. According to the indexes $\mathrm{H}^{\prime}$ and $\mathrm{J}^{\prime}$, diversity was highest at location 5 in the Alghero Gulf ( $3.3 ; 0.9$, respectively), followed by the
Orosei $(2.1 ; 0.9)$ and Asinara Gulfs $(1.3 ; 0.6)$ (Tab. 1 and Fig. 2).

Batillipedidae is the family represented by the highest density, ( 2 to 574 ind. $10 \mathrm{~cm}^{-2}$ ), followed by Halechiniscidae ( 2 to 263 ind. $10 \mathrm{~cm}^{-2}$ ) and Stygarctidae ( 0 to 13 ind. $10 \mathrm{~cm}^{-2}$ ). The highest total density was recorded in the Orosei Gulf in medium and coarse sands at depths of 1 and $5 \mathrm{~m}$ (sites 15 and 16) with 574 and 555 ind. $10 \mathrm{~cm}^{-2}$ respectively. The newly described species Batillipes spinicauda accounts for this density and represents $99 \%$ of the total number of individuals at these sites. Generally, B. spinicauda is also the most widely distributed species, encountered at 12 of the 18 sites.

Particle-size analysis of the sediments (Tab. 1) revealed medium or medium-fine intertidal sands and coarse subtidal sands, the latter primarily formed by coralligenous debris.

\section{DISCUSSION}

In general, Sardinian tardigrade fauna appears very rich and includes 47 species in family Halechiniscidae (30 species), Batillipedidae (9 species), Stygarctidae (4 species), Echiniscoididae (2 species), Neostygarctidae ( 1 species), and Neoarctidae ( 1 species), thus constituting $61 \%$ of the total number of species of the Mediter- 


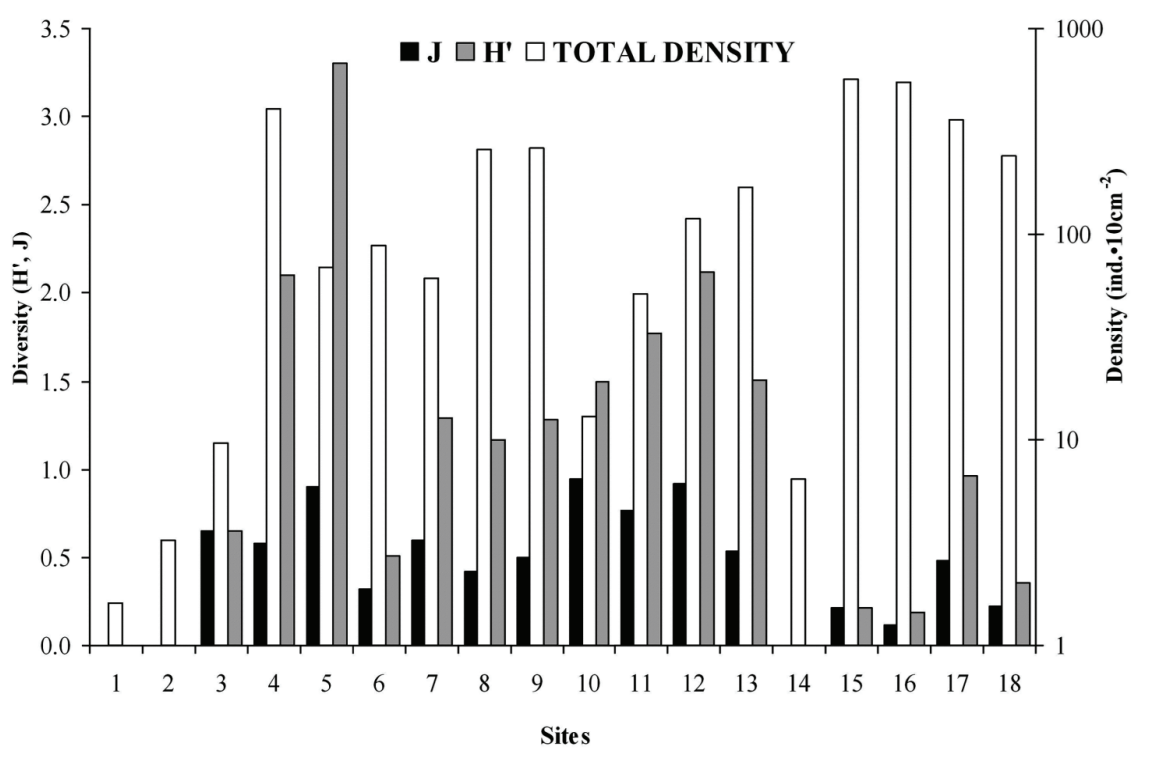

Fig. 2. Density (Log scale) and diversity of Sardinian tardigrade fauna.

ranean Sea. The distribution of tardigrades in the three gulfs is as follows: 3 families and 13 species has been recorded from the Orosei Gulf, while 3 and 2 families, and 21 and 10 species has been recorded from the Alghero and Asinara Gulf respectively. Until now, the Orosei Gulf seems to provide the best habitat, and it represents the widest distribution of tardigrades families and species.

Among the new records of Sardinia, it is worth noting the finding of (a) Parastygarctus mediterranicus Gallo D'Addabbo et al., 2001 at $30 \mathrm{~m}$ depth, previously known only from two subtidal caves at the Tremiti Islands; and (b) two new species, Florarctus n. sp. and Batillipes n. sp., in the Alghero Gulf.

Considering all previous and present data about Sardinian tardigrades, it seems evident that the subtidal zone is richer than the intertidal zone (39 and 15 species, respectively). This finding is in agreement with de Zio Grimaldi \& D'Addabbo Gallo (2001) who, in fact quote that of the 77 species known at that time in the Mediterranean Sea, only $4(5 \%)$ were exclusively intertidal, $20(26 \%)$ common to both intertidal and subtidal, and the remaining $53(69 \%)$ found only in the subtidal zone. These differences between intertidal and subtidal tardigrade fauna might not only depend on the physical conditions (i.e. wave action, granulometry, etc.), but (also) on the chemical composition of the sediment. The intertidal sands are in fact mainly siliceous, whereas the subtidal ones are calcareous with organogenous debris, known to be more attractive to meiofauna (Gallo D'Addabbo et al. 1999). Moreover, subtidal environments seem to be particularly suitable to the family Halechiniscidae, showing a much higher number of species in comparison to other families in this environment. In this respect, our data from the Mediterranean Sea are also in agreement with results from the North Atlantic
Sea by Hansen et al. (2001), who found a high number of species (35) in the Faroe Bank deep calcareous sediment, where the Halechiniscidae constituted the majority of species $(88 \%)$.

\section{ACKNOWLEDGMENTS}

We sincerely thank the anonymous reviewers for improving the quality of this paper.

\section{REFERENCES}

D'Addabbo Gallo, M., S. Grimaldi de Zio, M.R. Morone De Lucia \& A. Troccoli. 1992. Halechiniscidae and Echiniscoididae from the Western Mediterranean Sea. (Tardigrada: Heterotardigrada). Cah. Biol. Mar., 33: 299-318.

D'Addabbo Gallo, M., M.R. Morone De Lucia \& S. Grimaldi de Zio. 1989. Two new species of the genus Styraconyx (Tardigrada: Heterotardigrada). Cah. Biol. Mar., 30: 1733.

de Zio S. 1964. Distribuzione dei Tardigradi in spiagge pugliesi. Ann. Ist. Mus. Zool. Univ. Napoli, 16: 1-8.

de Zio Grimaldi, S. \& M. D'Addabbo Gallo. 2001. Further Data on the Mediterranean Sea tardigrade fauna. Zool Anz., 240: 345-360.

de Zio Grimaldi, S., M. D'Addabbo Gallo \& M.R. Morone De Lucia. 1992. Neoarctus primigenius n.g., n.sp., a new Stygarctidae of the Tyrrhenian Sea (Tardigrada: Arthrotardigrada). Boll. Zool., 59: 309-311.

de Zio Grimaldi S., M. Gallo D'Addabbo, R. Sandulli \& R. D'Addabbo. 2003. Checklist of the Italian marine Tardigrada. Meiofauna Mar., 12: 97-135.

Gallo D'Addabbo, M., S. de Zio Grimaldi, M.R. De Lucia Morone, R. Pietanza, R. D'Addabbo \& M.A. Todaro. 1999. Diversity and dynamics of an interstitial Tardigrada population in the Meloria Shoals, Ligurian Sea, with a redescription of Batillipes similis (Heterotardigrada, Batillipedidae). Ital. J. Zool., 66: 51-61.

Gallo D'Addabbo, M., S. de Zio Grimaldi, Sandulli, R. 2001. Heterotardigrada of two submarine caves in S. Domino Island (Tremiti Islands) in the Mediterranean Sea with the description of two species of Stygarctidae. Zool. Anz., 240: 361-369. 
Gallo D'Addabbo, M., R. Sandulli \& S. de Zio Grimaldi. 2005. A New Batillipedidae (Tardigrada, Heterotardigrada) from the Orosei Gulf, Sardinia, Tyrrhenian Sea. Zool. Anz., 243: 219-225.

Grimaldi, P. 1965. Osservazioni su alcuni elementi del mesopsammon della Sardegna. Monit. Zool. Ital., 73: 61-65.

Grimaldi de Zio, S., M. D'Addabbo Gallo \& M.R. Morone De Lucia. 1988. Two new Mediterranean species of the genus Halechiniscus (Tardigrada: Heterotardigrada). Boll. Zool., 55: 205-211.

Grimaldi De Zio, S., M. D'Addabbo Gallo \& M.R. Morone De Lucia. 1990a. Revision of the genus Halechiniscus. Cah. Biol. Mar., 31: 271-279.

Grimaldi de Zio, S., M. D'Addabbo Gallo, M.R. Morone De Lucia \& A. Troccoli. 1990b. New description of Neosty- garctus acanthophorus (Tardigrada, Arthrotardigrada). Cah. Biol. Mar., 31: 409-416.

Grimaldi de Zio, S., M.R. Morone De Lucia \& M. D'Addabbo Gallo. 1983. Marine Tardigrades Ecology. Oebalia, 9 N S.: $15-31$.

Hansen, J.G., M. Gallo D'Addabbo \& S. de Zio Grimaldi. 2003. A comparison of morphological characters within the genus Rhomboarctus (Tardigrada, Heterotardigrada) with the description of two new species. Zool. Anz., 242: 83-96.

Hansen, J.G., A. Jørgensen \& R.M. Kristensen. 2001. Preliminary Studies of the Tardigrade fauna of the Faroe Bank . Zool. Anz., 240: 385-393.

Higgins, R.P. \& H. Thiel. 1988. Introduction to the study of meiofauna. Smithsonian Inst. Press, Washington D.C.: 488 pp. 